\title{
PENGARUH MODEL PEMBELAJARAN GALLERY WALK BERBANTUAN TEKA-TEKI SILANG TERHADAP HASIL BELAJAR SISWA
}

\author{
Raudhah Awal ${ }^{1)}$ Devita Sari ${ }^{2)}$ \\ ${ }^{1), 2)}$ Pendidikan Biologi FKIP Universitad Lancang Kuning \\ Email $^{1)}$ : raudhahawal.unilak.ac.id \\ Email $^{2)}$ : saridevita620@gmail.com
}

\begin{abstract}
ABSTRAK: Konsep sistem pernapasan manusia merupakan salah satu konsep yang memiliki tingkat kesulitan yang cukup tinggi karena memiliki banyak penjelasan yang bersifat abstrak, sehingga dapat memicu terjadinya hasil belajar. Penelitian ini bertujuan untuk mengetahui pengaruh model pembelajar gallery walk berbantuan teka-teki silang terhadap hasil belajar siswa pada materi sistem pernapasan manusia kelas VIII MTs Negeri 2 Pekanbaru T.P 2018/1019. Penelitian ini dilaksanakan pada semester Genap bulan Januari. Desain penelitian ini yang digunakan adalah Quasi Eksperimen dengan The Metching Only Pretest-Posttest kontrol Group Design. Penelitian ini menggunakan dua kelas sampel. Sampelyang pertama adala kelas eksperimen VIII 3 dengan jumlah 27 siswa dan sampel yang kedua menggunakan kelas kontrol VIII 2 dengan jumlah 27 siswa. Sampel ditentukan dengan menggunakan teknik Purposive Sampling. Pengumpulan data dilakukan melalui Pretest, Posttest dan lembar observasi merupakan aktivitas guru dan siswa. Teknik analisis data menggunakan uji-t Indentpendent Samples Test. Berdasarkan hasil penelitian diketahui Rerata N-Gain pada kelas eksprimen adalah 0,71 kategori tinggi dan pada kelas kontrol adalah 0.37 kategori sedang. Berdasarkan analisis uji-t menunjukkan perbedaan yang signifikan anatar kelas eksperimen dan kelas kontrol. Dari hasil penelitian dapat disimpulkan bahwa terdapat pengaruh model pembelajaran gallery walk berbantuan teka-teki silang terhadap hasil belajar siswa pada materi sistem pernapasan manusia kelas VIII MTs Negeri 2 Pekanbaru T.P 2018/2019
\end{abstract}

Kata Kunci : Gallery walk, teka-teki silang,hasil belajar, sistem pernapasan

ABSTRACT: The concept of the human respiratory system is on of the concepts that has a fairly high level of difficulty because many explanations are abstract in nature, so that they can trigger learningoutcomes yu. The aim ofthis study is to determine the effect of gallery walk assisted by crossword puzzeles towards students learning achievement in human respiratory system material at class VIII Mts Negeri 2 Pekanbaru academic year 2018/2019. The design of thi study is quasi exsperiment with the matching only pretst-posttest control group design. This study used two 
class as the samples. The first sampel was class VIII 3 as an exsperiment, class with the number of 27 students. The second samples was class VIII 2 as a control class with the number of 27 student. The sample was determined by using simple random sampling. Data collection was done by pretest, posttest andobsevation sheet of teacher and students activities. The teachingue used to analyse the data was t-test Indentpendent Samples Test. Based on this study known that the average N-Gain of the exsperiment clas was 0,71 and categorized as high level while the control class was 0,37 and categorized as middle level. Based on the result of analyse using t-test show significant difference between exsperimentand control class. It can be concluded that gallery walk assisted by crossword puzzeles give towards students effect learning achievement in human respiratory system subjet at class VIII MTs Negeri 2 Pekanbaru academic year 2018/2019.

Keywords :walk gallery, crossword puzzles, learning achievement. respiratory system

\section{PENDAHULUAN}

Pendidikan adalah suatu proses usaha dalam mempengaruhi siswa agar dapat menyesuaikan diri sebaik mungkin terhadap lingkungannya dan dengan demikain akan menimbulkan perubahan dalam dirinya yang memungkinkan berfungsi dalam kehidupan bermasyarakat (Hamalik, 2010). Tujuan pendidikan adalah untuk mengembangkan kualitas manusia, sehingga dilaksanakan dalam suatu proses yang berkesinambungan pada setiap jenis dan jenjang pendidikan dalam suatu sistem secara integral. Ketercapaian tujuan pembelajaran membutuhkan suatu proses pembelajaran (Slameto, 2010).

Salah satu penentuan kesuksesan proses pembelajaran adalah guru. Guru tidak hanya memberikan pengetahuan ke dalam pemikiran siswa, namun juga harus merencanakan pengajaran dengan kegiatan yang melibatkan siswa secara aktif dalam membangun pengetahuan. Peningkatan mutu pendidikan itu tidak dapat dilaksanakan dengan baik oleh satu pihak saja. Keaktifan siswa salah satu prinsip utama dalam proses pembelajaran. Belajar dapat terjadi apabila ada aktivitas dari siswa, karena belajar lebih bersifat individu yang 
banyak dipengaruhi oleh potensi dan kemampuan individu. Inisiatif yang datang dari siswa dapat membantu efektivitas dan efisiensi pembelajaran, karena belajar sangat berhubungan dengan apa yang harus dikerjakan (diperbuat) siswa untuk dirinya sendiri maupun kelompoknya (Zain, 2002).

Guru dalam konteks pendidikan mempunyai peranan yang besar dan strategis. Hal ini disebabkan karena gurulah yang berada dibarisan terdepan dalam pelaksanaan pendidikan. Gurulah yang berhadapan langsung dengan peserta didik untuk mentransfer ilmui-ilmu pengetahuan dan teknologi sekaligus mendidik dengan nilai-nilai positif melalui bimbingan dan keteladanan (Kunandar, 2008).

Berdasarkan hasil observasi di MTs Negeri 2 Pekanbaru melalui wawancara diperoleh informasi langsug dari guru IPA bahwa hasil belajar siswa kelas VIII T.P 2017/2018 pada materi sistem pernapasan manusia adalah rendah, dari total 140 orang siswa, hanya 45 siswa yang tuntas $(57,7 \%)$ mencapai KKM. KKM (Kriteria Ketuntasan Minimal) ditetapkan sekolah untuk pembelajaran biologi di MTs Negeri 2 Pekanbaru yaitu 75 dari skor 100. Berdasarkan hasil wawancara dengan guru IPA diketahui bahwa tidak semua siswa yang memiliki buku IPA, serta kurang nya keaktifan siswa dalam proses pembelajaran. Selain itu kurangnya diterapkan model pembelajaran sehingga membuat siswa tidak fokus belajar IPA, siswa sering merasa bosan sehingga nilai pelajaran biologi rendah.

Siswa kelas VIII MTs Negeri 2 Pekanbaru pada umumnya menganggap bahwa pelajaran biologi itu membosankan karena materinya penuh hapalan. Pada umumnya siswa menganggap pelajaran biologi adalah banyak istilah biologi yang membingungkan walaupun memiliki arti yang sederhana. Sehingga menjadikan siswa pasif dalam pembelajaran dan hasil pembelajarannya kurang baik. Kepasifan itu salah satunya 
dikarenakan model pembelajaran yang digunakan guru monoton, guru sering menggunakan model ceramah tanpa melibatkan keaktifan siswa.

Untuk mencapai tujuan belajar tersebut diperlukan adanya ketepatan guru dalam memilih model pembelajaran yang sesuai dengan materi pembelajaran. Model belajar guru yang kurang baik akan mempengaruhi cara belajar siswa ,Siswa cenderung kurang bersemangat dan cepat bosan dengan pelajaran yang diberikan oleh guru. Hal tersebut timbul akibat kurangnya kemampuan guru dalam menguasai pelajaran yang diberikan kepada siswa, akibatnya siswa malas untuk belajar (Slameto, 2010). Salah satunya model pembelajaran Gallery Walk yang merupakan suatu metode yang menuntut siswa untuk lebih aktif dalam proses pembelajaran.

Gallery Walk adalah model pembelajaran yang dapat memaksa siswa untuk membuat suatu daftar baik berupa gambar maupun skema sesuai hal-hal apa yang ditemukan atau diperoleh pada saat diskusi di setiap kelompok untuk dipajang di depan kelas. Setiap kelompok menilai hasil karya kelompok lain yang digalerikan, kemudian dipertanyakan pada saat diskusi kelompok dan ditanggapi. Penggalerian hasil kerja dilakukan pada saat siswa telah mengerjakan tugasnya. Setelah semua kelompok melaksanakan tugasnya, guru memberi kesimpulan dan klarifikasi sekiranya ada yang perlu diluruskan dari pemahaman siswa. Dengan demikian mereka dapat belajar dengan lebih menyenangkan sehingga tujuan pembelajaran yang diharapkan bisa tercapai (Ismail, 2008).

Kelebihan dari model pembelajaran gallery walk ini adalah dapat memberi semangat belajar serta pengalaman yang sangat berharga bagi siswa; Siswa terbiasa membangun budaya kerja sama memecahkan masalah dalam belajar; Terjadi sinergi saling meguatkan pemahaman terhadap tujuan pembelajaran; 
Membiasakan siswa bersikap yang sesuai atau cocok dengan menghargai dan mengapresiasi hasil pertanyaan yang nantinya akan belajar kawannya; Mengaktifkan fisik membentuk kata yang saling dan mental siswa selama proses belajar; Membiasakan siswa bersikap menghargai dan mengapresiasikan hasil belajar kawannya; Membiasakan siswa memberi dan menerima kritik; Siswa tidak perlu menggantungkan pada guru, akan tetapi dapat menambah keparcayaan kemampuan berpikir sendiri, menemukan informasi dari berbagai sumber, dan belajar dari siswa yang lain (Ismail, 2008).

Model pembelajaran gallery walk dapat dipadukan dengan media ajar teka-teki silang. Teka Teki Silang (TTS) yang merupakan media ajar pembelajaran yang tepat digunakan untuk mengefektifkan komunikasi dan interaksi guru dengan siswa dalam proses pembelajaran di sekolah. Dengan demikian yang dimaksud dengan media teka-teki silang adalah media yang dirancangan sedemikian rupa dengan pertanyaan menurun atau mendatar, sehingga diperoleh jawaban

Teka-teki silang adalah sebuah permainan untuk mengasah otak. Teka-teki silang dapat dimanfaatkan dalam bidang pendidikan untuk menguji kemampuan anak didik, sehingga pertanyaan-pertanyaan yang digunakan disesuaikan dengan kebutuhan saja. Tapi akan sulit apabila jumlah pertanyaaan yang digunakan terlalu banyak, karena untuk membuat sebuah teka-teki silang dari kumpulan pertanyaan kita harus mecoba kombinasi yang mungkin dari kata yang ada sampai berbentuk sebuah teka-teki silang. Semakin banyak jumlah pertanyaan, maka semakin 
banyak kombinasi yang akan dicoba (Hendra, 2008).

Berdasarkan latar belakang yang dikemukakan diatas maka penulis melakukan penelitian yang berjudul "Pengaruh model pembelajaran Gallery Walk berbantuan teka-teki silang terhadap hasil belajar siswa pada materi sistem pernapasan manusia di kelas VIII MTs Negeri 2 Pekanbaru".

Tujuan penelitian ini adalah untuk mengetahui pengaruh model pembelajaran galleri walk berbantuan teka teki silang terhadap hasil belajar siswa pada materi sistem pernapasan manusia di kelas VIII MTs Negeri 2 Pekanbaru T.P 2018/2019.

\section{METODE PENELITIAN}

Penelitian ini merupakan penelitian eksperimen Penelitian eksperimen adalah suatu penelitian yang dilakukan untuk mengetahui pengaruh pemberian suatu treatmen atau perlakuan terhadap subjek penelitian

Populasi Penelitian ini adalah siswa kelas VIII di MTs Negeri 2 Pekanbaru yang terdiri dari 5 kelas, Bio-Lectura: Jurnal Pendidikan Biologi, Vol 6, No 2, Oktober 2019 yang berjumlah 137 orang siswa. Sampel penelitian diambil dengan teknik purposive sampling, sehinggga didapat satu kelas eksperimen yaitu kelas $\mathrm{VIII}_{3}$ dengan jumlah siswa 27 orang dan satu kelas kelas kontrol yaitu kelas $\mathrm{VIII}_{2}$ yang berjumlah 27 orang siswa.

Parameter yang akan diamati dalam penelitian ini adalah. Hasil belajar siswa aktivitas Siswa, aktivitas Guru

Parameter yang diamati dalam penelitian adalah hasil siswa dalam hasil belajaran dalam pembelajaran sistem pernapasan manusia aktivitas guru dalam proses belajar mengajar dapat dievaluasi melalui lembar observasi ,dan aktivitas siswa yang dapat diukur dengan menggunakan lembar observasi aktivitas siswa

\section{HASIL DAN PEBAHASAN}

Berdasarkan data hasil penelitian yang telah dilakukan pada bulan Januari 2019 di kelas VIII MTs Negeri 2 Pekanbaru pada kelas VIII 3 sebagai kelas eksperimen dan VIII 2 sebagai 
kelas kontrol maka diperoleh data rekapitulasi pretest sebagai berikut:

a. Analisis Data $N$-Gain

Hasil $N$-Gain pada kelas eksperimen dan kelas kontrol adalah sebagai beikut:

Tabel 21 : Statistik Deskriptif Nilai $N$-Gain

\begin{tabular}{|c|c|c|c|c|c|c|c|}
\hline \multirow[t]{2}{*}{ No } & \multirow[t]{2}{*}{ Kelas } & \multirow[t]{2}{*}{$\mathrm{n}$} & \multicolumn{3}{|c|}{ Nilai- $N$-Gain } & \multirow[t]{2}{*}{ Rerata } & \multirow[t]{2}{*}{ Kategori } \\
\hline & & & Ideal & Minimum & Maksimum & & \\
\hline 1 & Eksperimen & 27 & 1,00 & 0,48 & 0,90 & 0,71 & Tinggi \\
\hline 2 & Kontrol & 27 & 1,00 & 0,06 & 0,65 & 0,37 & Sedang \\
\hline
\end{tabular}

Berdasarkan Tabel 21 nialai $N$ -

nilai $N$-Gain kelas kontrol adalah 0,37

Gain minimum kelas eksperimen (kategori sedang)

adalah 0,48 sedangkan kelas kontrol

b. Aktivitas Guru dan siswa nilai minimum 0,06. Hasil nilai berikut ini erupakan hasill observasi maksimum $N$-Gain kelas eksperimen aktivitas guru kelas kontrol dan adalah 0,90 sedangkan kelas kontrol nilai maksimum adalah 0,65 . Rerata nialai $N$-Gain kelas eksperimen adalah eksperimen pertemuan 1 sampai Pertemua II yang tertdapat pada tabel berikut

0,71 (kategori tinggi) sedangkan rerata

Tabel 25 : Rekapitulasi Aktivitas Guru

\begin{tabular}{|c|c|c|c|}
\hline Kelas & Pertemuan I (\%) & Pertemuan II (\%) & Rerata (\%) \\
\hline Eksperimen & 87,50 & 100 & 93,75 \\
\hline Kontrol & 55,5 & 77,7 & 83,3 \\
\hline
\end{tabular}

$\begin{array}{llrl}\text { Berdasarkan } & \text { Tabel } & 25 & \text { kelas kontrol pertemuan I dan II } \\ \text { diketahui aktivitas } & \text { guru kelas } & \text { presentasenya mencapai } 55.55 \% \text { dan } \\ \text { eksperimen pada pertemuan I dan II } & 77,77 \% \text {, dengan rerata presentase } \\ \text { presentasenya adalah } 87,50 \% \text { dan } & \text { 83,3\%. Peningkatan aktivitas kelas } \\ \text { 100\%. dengan rerata presentasi } & \text { eksperimen dan kontrol dapat dilihat } \\ 93,75 \% \text {. Sedangkan pada ativitas guru } & \text { pada tabel dibwah ini: }\end{array}$

Bio-Lectura: Jurnal Pendidikan Biologi, Vol 6, No 2, Oktober 2019 
Tabel 26 : Rekapitulasi Aktivitas Siswa Kelas Eksperimen

\begin{tabular}{|c|c|c|c|c|c|c|c|}
\hline \multirow{2}{*}{ Pertemuan } & \multicolumn{6}{|c|}{ Aktivitas (\%) } & \multirow{2}{*}{$\begin{array}{c}\text { Rerata } \\
\text { Presentasi } \\
(\%)\end{array}$} \\
\hline & 1 & 2 & 3 & 4 & 5 & 6 & \\
\hline I & 100 & 81,48 & 88,88 & 100 & 100 & 100 & 95,05 \\
\hline II & 100 & 92,59 & 96,29 & \multicolumn{2}{|c|}{100 diskt@Q } & \multicolumn{2}{|c|}{ 10felompok98,14 p } \\
\hline
\end{tabular}

pertuman I dan II adalah $100 \%$. Lalu

Berdasarkan Tabel 26 terlihat bahwa terdapat kenaikan rerata persentase aktivitas siswa kelas eksperimen dari pertemuan I hingga pertemuan II dimana menemoati diri dalam kelompok dengan cepat, persentase pertemuan I dan II adalah $100 \%$ dan 100\%. Lalu aktivitas ke-2 mencari jawaban sesuai tugas yang diberikan, persentase pertemuan I dan II adalah $81,48 \%$ dan $92,59 \%$. Kemudian pada aktivitas ke-3 siswa menempel hasil belajar di dinding, persentase pertemuan I dan II yaitu $88,88 \%$ dan $96,29 \%$. Lalu aktivitas ke4 siswa mempresentasikan hasil

Tabel 27 : Rekapitulasi Aktivitas Siswa Kelas Kontrol

\begin{tabular}{|c|c|c|c|c|c|}
\hline \multirow{2}{*}{ Pertemuan } & \multicolumn{4}{|c|}{ Aktivitas (\%) } & $\begin{array}{c}\text { Rerata } \\
\text { Presentasi } \\
(\%)\end{array}$ \\
\cline { 2 - 5 } & 1 & 2 & 3 & 4 & 53,70 \\
\hline I & 44,44 & 48,14 & 33,33 & 100 & 61,11 \\
\hline II & 48,14 & 44,44 & 51,85 & 100 & \\
\hline
\end{tabular}


Berdasarkan Tabel 27 terlihat bahwa rerata presentase aktivitas siswa kelas kontrol dari pertemuan I hingga pertemuan II terdapat kenaikan persentase yang signifikan. Dimana aktivitas siswa pada pertemuan I dan II pada bagian siswa mencatat materi sistem pernapasan sistem pernapasan yang dijelaskan oleh guru pertemuan I dan II adalah 44,44\% dan 48,14\%. Lalu aktivitas ke-2 siswa mengajukan pertanyaan kepada guru, persentase pertemuan I dan II adalah 48,14\% dan $44,44 \%$. Kemudian pada aktivitas ke-3 siswa menjawab/merespon pertanyaan dari guru, persentase pertemuan I dan II yaitu $33,33 \%$ dan $51,85 \%$. Lalu aktivitas ke-4 siswa mengerjakan evaluasi, persentase pertemuan I dan II adalah 100\%. Rerata persentase pertemuan I dan II adalah 53,70\% dan $61,11 \%$ mengalami peningkatan.

\section{KESIMPULAN}

Berdasarkan hasil penelitian dan analisis data dapat disimpulkan bahwa terdapat pengaruh model pembelajaran gallery walk berbantuan teka-teki silang terhadap hasil belajar siswa pada materi sistem pernapasan manusia kelas VIII MTs Negeri 2 Pekanbaru T.P 2018/2019. Peningkatan hasil belajar dapat dilihat dari hasil $N$-gain Pada kelas eksperimen sebesar 0,71 (kategori tinggi) dan $\mathrm{N}$-Gain pada kelas kontrol sebesr 0,37 (kategori sedang). Berdasarkan hasil uji-t N-Gain diketahui terdapat perbedaan signifikan antara kelas eksperimen dan kelas kontrol

\section{SARAN}

Berdasarkan hasil penelitian yang telah dilakukan, disarankan agar peneliti berikutnya lebih cermat memantau dan menilai keaktifan individu siswa. Hal ini dikarenakan banyak terjadi siswa menggantungkan kerja kepada kawannya, serta pengaturan setting kelas yang lebih rumit. 


\section{DAFTAR PUSTAKA}

Anni, C, T, (2007). Psikologi Belajar. UPT Unnes Press: Semarang

Arikunto, (2011). Prosedur Penelitian Suatu Pendekatan Praktik. Rineka Cipta: Jakarta

Dimyati \& Mudjiono. (2013). Belajar dan Pembelajaran. Rineka Cipta: Jakarta.

Gufron, M. (2011). Implementasi Metode Gallery Walk dan Samll Group Discussion Dalam Meningkatkan Efektifitas Pembelajaran Agama Islam Kelas VIII E Di SMP Negeri 1 Banyuanyar Probolinggo. Skripsi Jurusan Pendidikan Agama Islam Universtas Negeri Islam Maulana Malik.

Hafni. (2010). Media Teka-Teki Silang. Kencana:Jakarta

Hamalik, O. (2010). Proses Belajar Mengajar. Bumi Aksara: Jakarta

Hendra. (2008). Teka-teki Silang. Kencana:Jakarta.

Hidayat. (2009). Teka-teki Silang. Kencana:Jakarta.

Ismail. (2011). Gallery Walk Teori dan Aplikasi Belajar. Pustaka Pelajar: Yogyakarta

Kunandar. (2008). Guru Profesionlan Implementasi Kurikulum Timgkat Satuan Pendidikan
(KTSP) dan Sukses dalam Sertifikasi Guru. Raja Grafinda Peersada: Jakarta.

Mariam, F.S. (2010). Pembelajaran Berbasis Proyek Metode Gallery Walk Untuk Meningkatan Hasil Belajar Siswa Pada Materi Sistem Ekresi Manusia. Jurnal Pendidikan Biologi, Volume. II. November 3 Hal.17-21

Mc Millan, J.H \& Schumacher,S.(2001).Resarch In Education. Logman: New York

Nuh, M. (2014). Ilmu Pengetahuan Alam. Kemdikbud: Jakarta

Rakhmayanti, R, Fitri, A. H. dan Handayani (2018). Penerapan Metode Gallery Walk Terhadap Kreativitas Siswa Pada Materi Pencemaran Lingkungan Di Kelas X SMA Negeri 1 Gersik. Jurnal Pendidikan Biologi, Volum 10 Nomor. 2 Hal 20-23

Silberman. (2013) Pembelajaran Gallery Walk. Yoppodis: Yogyakarta

Sardirdiman, S. (2014). Intraksi Dan Motivasi Belajar Mengajar. Raja Grafindo Persada: Jakarta Slameto. (2010). Belajar dan Faktorfaktor yang Mempengaruhinya. Rineka Cipta Karya : Jakarta

Sugiyono. (2007). Metode Penelitian. Tristo: Bandung

Bio-Lectura: Jurnal Pendidikan Biologi, Vol 6, No 2, Oktober 2019 
Suprijono, A. (2009). Multimedia Interaktif. Graha Ilmu : Yogyakarta

Widarti, S., Peniati, W. dan Widyaningrum, P. (2013). Pembelajaran Gallery Walk Berpendekatan Contextual Teaching Learning Materi Sistem Pencernaan Di SMA. Negeri 1 Gringsing. Journal
Unnes. Volume. 2. Nomor. 1. Hals 11-17 FMIPA Universitas Negeri Semerang. Semarang

Zain, A. (2002). Strategi Belajar Mengajar. Rineka Cipta: Jakarta

Zulfan. (2009). Teka-teki Silang ,Kencana:Jakarta. 